\title{
Antioxidant effect of Lonicera Caerulea on heat stress-treated male mice
}

\author{
Donghun Kang and Daeyoung Kim* \\ Department of Life Science, College of Bio-Nano Technology, Gachon University, Seongnam 13120, Korea
}

Received November 27, 2021

Revised December 14, 2021

Accepted December 15, 2021

\section{*Correspondence}

Daeyoung Kim

E-mail: davekim@gachon.ac.kr

Author's Position and Orcid no. Kim D, Professor, https://orcid.org/0000-0003-1608-8441 Kang D, Ms student,

https://orcid.org/0000-0002-4080-8915

\begin{abstract}
Lonicera caerulea (Honey berry, HB) has been used in medical treatment in Russia, Japan, China and Korea. It has high level of vitamin C and polyphenolics. Polyphenolics can improve anti-inflammatory effect and prevent cancer, diabetes mellitus type 2. Also, Vitamin C is a representative anti-oxidant. however, it is still unknown what effect it will have on the oxidation stress of the reproductive system. In previous studies, ROS can be produced when it is exposed to heat stress and has negative effect on sperm's maturation, capacitation, hyperactivation, acrosome reaction and fusion of egg and sperm. Therefore, the purpose of this study is to investigate the antioxidant effects of L. Caerulea on the sperm and mice. At first, it conducted using ICR mouse $(n=20)$ for 4 weeks. There are four groups of mice $(n$ $=5$ per group). Also, L. Caerulea was taken by oral gavage. Group I (control) kept at $23^{\circ} \mathrm{C}-27^{\circ} \mathrm{C}$ and administer D.W $(0.5 \mathrm{~mL} /$ day), Likewise, Group II (HB) kept at room temperature but gave HB (250 mg/kg, $0.5 \mathrm{~mL} /$ day), Group III (HB + HS) received heat stress $\left(40^{\circ} \mathrm{C}\right)$ using hyperthermia induction chamber and gave $\mathrm{HB}$ at same dose. and Group IV (HS) exposed heat stress only. Mainly, we showed degree of gene expression using Western blot in SOD, HSP 70, 17 $\beta$-HSD and Real-time PCR. It can find correlation between intracellular activity like steroid hormone, apoptosis under ROS and antioxidant activity of L. Caerulea.
\end{abstract}

Keywords: antioxidant, heat stress, Lonicera caerulea, mouse, testis

\section{INTRODUCTION}

Over the past few decades, the increasing number of infertility factors in young men worldwide and the gradual deterioration of sperm quality have led to lower sperm parameters proposed by the World Health Organization (WHO) (Cohen et al., 2015). There is growing evidence that human sperm quality is declining. Decreased sperm quality is caused by exposure to negative lifestyle habits such as obesity, cell phone use, smoking, and alcohol consumption (Dissanayake et al., 2019). Among them, the most direct cause is genital heat stress due to high tes- ticular heat, which is a real risk factor for male infertility. The testes are the male reproductive organs responsible for sperm production. In mammals, the temperature of the testes to form normal sperm must be $2-8^{\circ} \mathrm{C}$ below body temperature. Heat stress is applied to the testicles in daily living environments such as prolonged sitting or exposure to radiant heat, varicose veins, latent orchiopathy, over-the-lap use of laptops, sauna, and warm baths (Durairajanayagam et al., 2015; Hamilton et al., 2016). In elevated testicular temperature, sperm stem cells are damaged, affecting the differentiation and proliferation of sperm (Ahn et al., 2020). In addition, heat stress and 
chemical stress generate ROS and induce apoptosis (An et al., 2021). ROS increases the expression of TRPV1 and induces apoptosis of Leydig cells (Kim et al., 2021). Besides, it induces heat shock protein production and causes spermatogenesis arrest, germ cell death, and DNA damage in sperm. For these, serious problems, the male genital tract utilizes antioxidant mechanisms to resist heat stress, but it is still unknown. However, this does not mean that there are no effective methods for heat stress. Previous studies have shown that curcumin and mucuna pruriens contain a large amount of polyphenol, which has a chemical protective effect (Jang et al., 2009; Suresh et al., 2011). Likewise, L. Caerulea contains phenol and vitamin C, which can prevent cancer, diabetes, and cardiovascular disease, lower blood pressure and slow the aging process. This effect can suppress the oxidative effect caused by heat stress and protect the testicles (Sochor et al., 2014; Liu et al., 2018; Molina et al., 2019; Shahat et al., 2020). In the heat-stressed testis, the expression level of $17 \beta-H S D$ decreased, Hsp70 and Caspase 3, which are heat shock proteins, increased, and eventually, testosterone levels decreased. Decreased testosterone and increased ROS affect negative morphological changes in testicular tissue, and damage to seminiferous tubule and Leydig cells in the altered testicular tissue causes DNA changes in both immature sperm and mature sperm, resulting in the formation of malformed sperm (Labrie et al., 1997; Chang et al., 2014; Durairajanayagam, 2015; Alotaibi, 2020; Cai et al., 2021). It's possible. Similarly, changes in Leydig cells affect the expression of androstenedione, leading to a decrease in the expression of testosterone. When $\mathrm{L}$. Caerulea is ingested, the testicular tissue damage caused by such severe heat stress increases the cell's antioxidant action to protect the testicles from heat stress. L. Caerulea contains a large amount of polyphenol and L-ascorbic, which shows an antioxidant effect against increased ROS (Andrade and Fasolo, 2014; Hidalgo and Almajano, 2017). Polyphenol promotes the expression of antioxidant enzymes by increasing the expression levels of miRNA and Nrf2 related to antioxidant (Kim and Keum, 2016; Zhou et al., 2019). H2O2 reacts with superoxide anions formed in oxidative metabolism to generate hydroxyl radicals. Lascorbic is a well-known antioxidant that works as a peroxidase and removes the formed radicals to convert $\mathrm{H} 2 \mathrm{O} 2$ to $\mathrm{H} 2 \mathrm{O}$, preventing oxidative stress caused by heat shock (Vijayprasad et al., 2014; Sun et al., 2019). As oxidative stress is reduced by L. Caerulea, $17 \beta-$ HSD is normally expressed, and the levels of androstenedione and aromatase testosterone are also normally expressed. However, tissue changes caused by thermal shock cannot fully restore testicular function. However, by stopping the continuous tissue damage, it can minimize the sequelae, activate tissue reconstruction, and suppress infertility.

\section{MATERIALS AND METHODS}

\section{Animal}

Gachon University approved all experiments, and each 4-week-old ICR mice were purchased from Doo Yeol Biotech. The animals were raised 1week in the animal room of the Gachon University bionano research institute. This study was conducted in male ICR mice for 4 weeks. Animals were managed in a restricted environment with Purina laboratory animal diets, water, and constant temperature. All procedures were performed according to the protocol approved by IACUC (GIACUC-R2017036) of the Animal Experimental Ethics Committee of Gachon University.

\section{Experimental design}

The total number of mice was $n=20$, with the experimental groups ( $n=15)$ male ICR mice, respectively, and the groups were classified as A, B, C, and D. A is a control group $(C, n=5), B$ is a honey berry group $(H B, n=5), C$ is a heat stress group ( $\mathrm{HB}, \mathrm{n}=5)$, and $\mathrm{D}$ is a combination group of heat stress and honey berry (HB $+\mathrm{HS}, \mathrm{n}=$ 5). Group A (negative control) was subjected to the same stress as the experimental group by oral administration of D.W (0.5 mL/day). Honeyberry was diluted to a concentration of $250 \mathrm{mg} / \mathrm{kg}$ and orally administered at $0.5 \mathrm{~mL} /$ day. The HS group and the HB + HS group were received to heat stress on the testes in a water bath at $42^{\circ} \mathrm{C}$ for 30 minutes.

\section{RESULTS}

\section{Weight measure (Fig. 1)}

Individual body weights of 9-weeks-old mice were measured at necropsy. Adrenal gland, heart, liver, lung, salivary glands, spleen, and testis weights were also measured after autopsy. Rats were always weighed and fasted for 6 hours prior to necropsy, but there were no restrictions on 


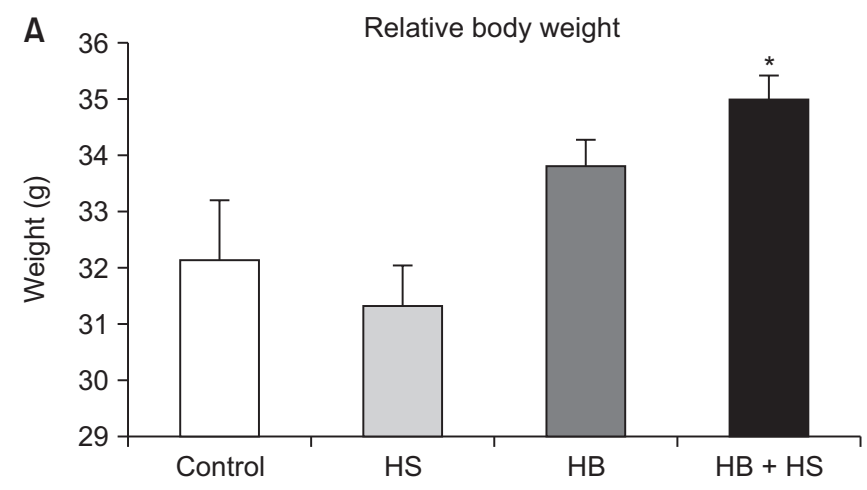

B

Relative liver weight
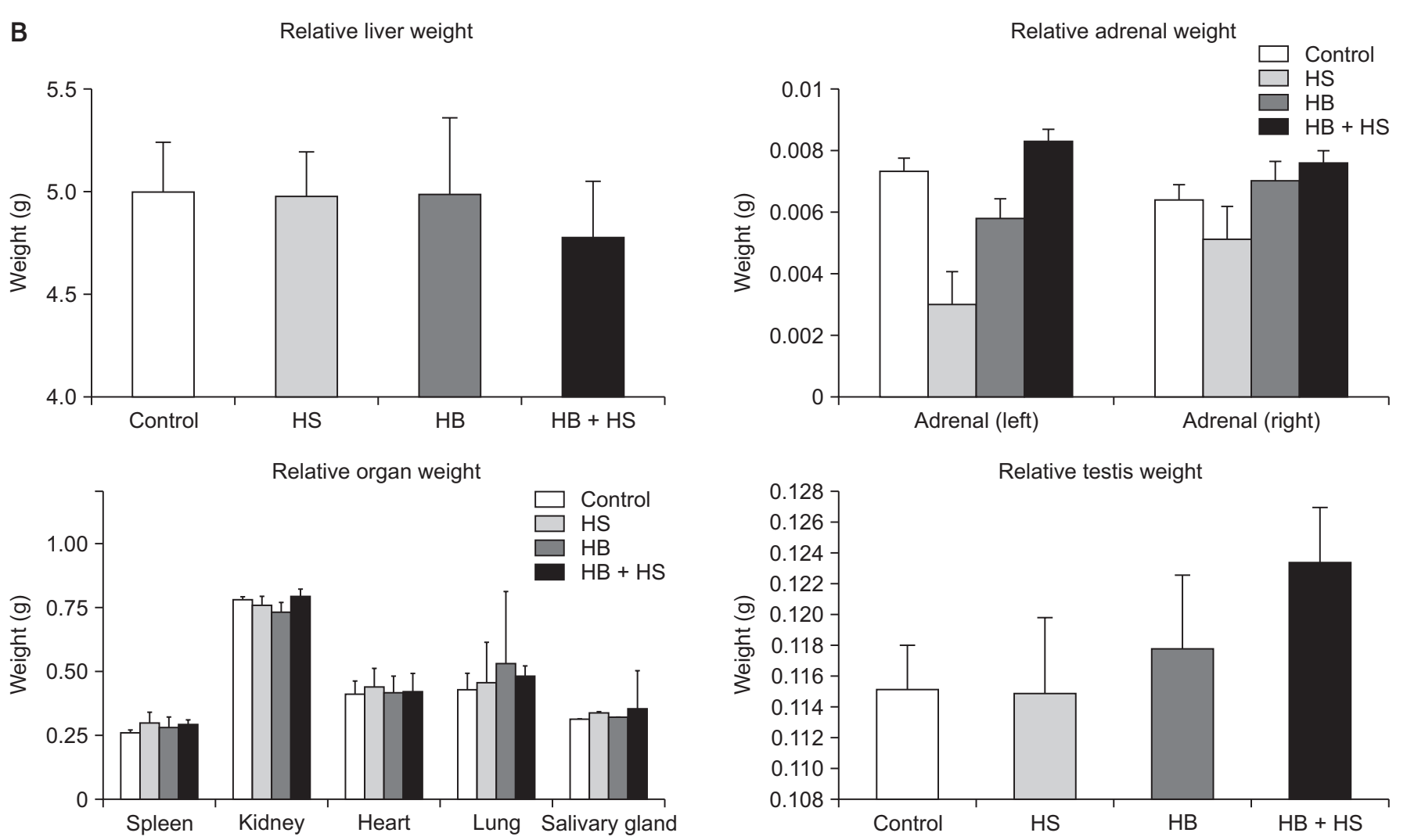

Fig. 1. Effects of Lonicera caerulea $(250 \mathrm{mg} / \mathrm{kg}, 0.5 \mathrm{~mL} /$ day) administration on body and testis weight of mice after 4 weeks. (A) body weight and (B) Organ weight. HS (Heat shock group). HB (Honey berry group), HB + HS (Honey berry + Heat shock group). Compared to the control group, the HS group had a relatively reduced weight, but the liver weight was measured relatively similarly. However, due to thermal shock, adrenal gland emptying was reduced, and testicular weight was also reduced. HB + HS group, compared to the control group, the body weight increased significantly, and the weight of the testes increased even after receiving a thermal shock. Value is mean \pm SD of 4 mice group (SPSS, Tukey HSD, $n=20$ ), ${ }^{*} p<0.05$ vs. the control group.

water supply.

\section{WBC differential count (Fig. 2)}

9-weeks-old mice tissue samples were obtained from blood samples were obtained from abdominal veins at the same time as autopsy. A total complete blood cells (CBC) were each analyzed for WBC count total $C B C$ measured WBC using an Advia ${ }^{\circledR} 2120$ i (hematology system, Siemens,
Germany). Basophil, Eosinophil, Leukocyte, Monocyte, Neutrophil, MPXI (Myeloperoxidase Index), and WBCP (Whole blood coagulation profile) were measured in the WBC count.

\section{Computer-Assisted Semen Analysis (CASA) (Fig. 3)}

Computer-Assisted Semen Analysis is a method of automatically or semi-automated Semen analysis using a 

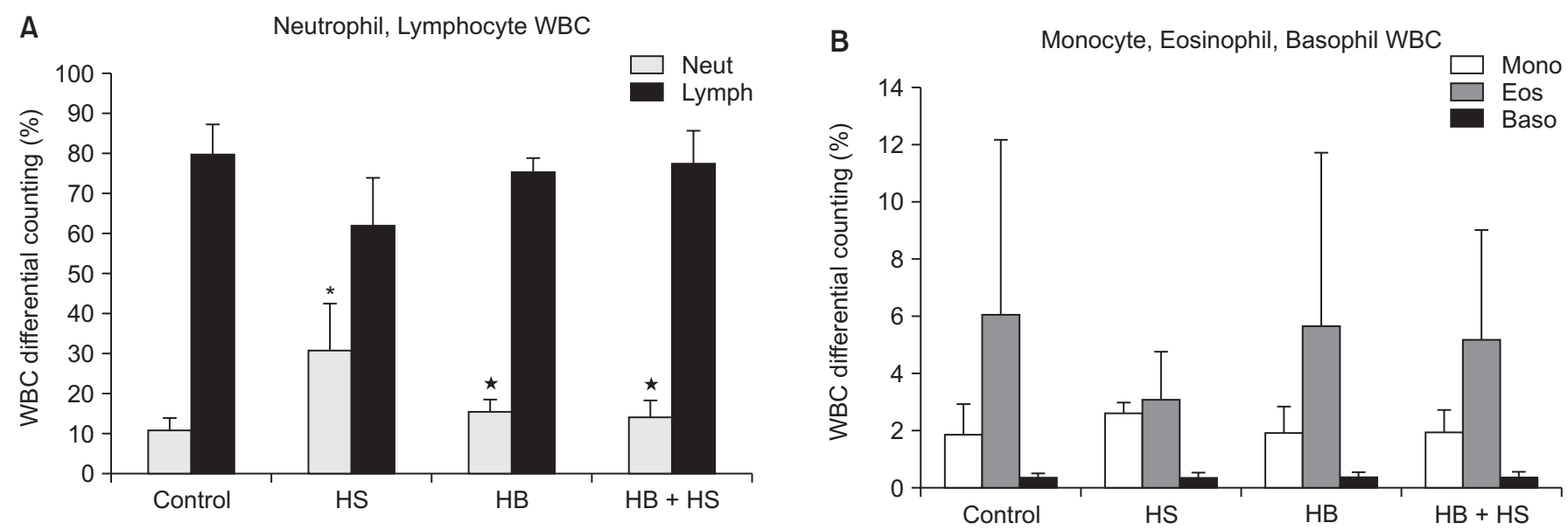

Fig. 2. White blood cell count (WBC) (cells/uL) in mice 4 weeks after administration of Lonicera caerulea $(250 \mathrm{mg} / \mathrm{kg}, 0.5 \mathrm{~mL} / \mathrm{day}) . \mathrm{HS}$ (Heat shock group), HB (Honey berry group), HB + HS (Honey berry + Heat shock group). (A) Neutrophil and Lymphocyte WBC. HS groups significantly increased the number of neutrophils compared to the control group. The number of neutrophils increased due to damage to the testicular tissue by thermal shock. In the case of the HB group, there was no significant difference when compared with the control group, and there was a significant decrease when compared with the HS group. On the other hand, the HB + HS group damaged testis and leukocyte DNA by heat shock, but the number of neutrophils increased due to the antioxidant effect of a large amount of polyphenol contained in HB. Lymphocyte results showed no significant difference. (B) Monocyte, Eosinophil, and Basophil WBC, in the HB + HS group, the number of leukocytes appears to be increased due to the recovery response from heat shock. but there was no significant difference in the results for Monocyte, Eosinophil, and Basophil. Value is mean \pm SD of 4 mice group (SPSS, Tukey HSD, $\mathrm{n}=20$ ), ${ }^{*} p<0.05$ vs. the control group, ${ }^{\star} p<0.05$ vs. the HB group.

computer. Most systems are based on image analysis, but alternative methods exist, such as tracking sperm movement on a digitizing tablet. Analytical results are most often used to evaluate concentration, velocity and linear velocity, mobility. In this experiment, the number of sperm in each group was measured and analyzed (Amann and Waberski, 2014).

\section{Western blot (Fig. 4)}

Quantitatively comparing the expression levels of $17 \mathrm{be}-$ ta-HSD between groups, the degree of testicular damage caused by heat stress was predicted and the protective effect of honey berry from oxidative stress increased by heat stress was measured.

\section{Serum testosterone level (Fig. 5)}

Blood specimens were collected from the abdominal vein of anesthetized mouse and plasma was separated and stored in $-20^{\circ} \mathrm{C}$ freezers for biochemical tests. Testosterone hormone level was measured by enzyme-linked immunosorbent assay (ELISA) according to the kit manufacturer's instruction. These kits use a double-antibody sandwich ELISA. A series of standard solutions was prepared. First, the primary antibody was added to the 96-well plate (not to control wells). A $50 \mu \mathrm{L}$ aliquot of standard solution or $40 \mu \mathrm{L}$ sample was added to the designated wells. Secondary antibody (labeled with Streptavidin-HRP) was then added to the standard and sample wells. The plates were incubated at $37^{\circ} \mathrm{C}$ for 60 min. Plates were washed, then chromogenic solutions (A, B) were added under darkness and incubated for $10 \mathrm{~min}$ at $37^{\circ} \mathrm{C}$. Chromogenic and stop solutions were added only to the control wells. Using an ELISA reader, the absorbance of wells at $450 \mathrm{~nm}$ wavelengths was read after the stop solution was added to the wells (Model State fax 2010). A standard curve was extrapolated based on the readings from the standard wells, and a linear regression equation was calculated. Sample concentration levels were calculated based on the OD readings and the standard curve.

\section{H\&E staining (Fig. 6)}

Staining was performed to visually compare the degree of damage to testicular tissue caused by heat stress. Formalin-fixed testis samples were fixed with $4 \%$ neutral formaldehyde, dehydrated in ethanol, and then embedded 

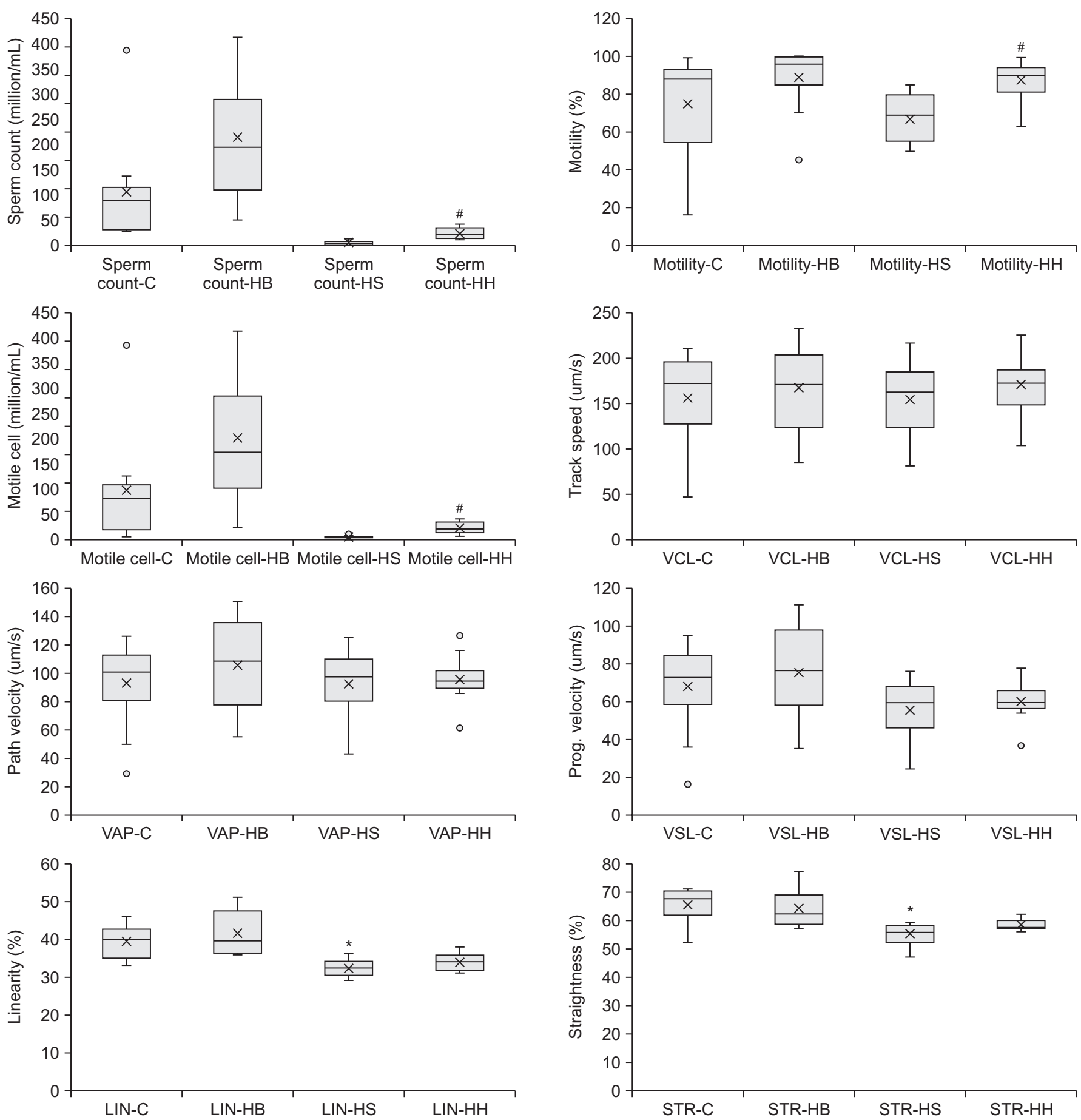

Fig. 3. Computer-assisted sperm analyses (CASA) results of mouse sperm 4 weeks after administration of Lonicera caerulea (250 mg/ $\mathrm{kg}, 0.5 \mathrm{~mL} /$ day). CASA of epididymal sperm were collected from control group (C), Honey berry group (HB), Heat shock group (HS), Honey berry + Heat shock group $(\mathrm{HB}+\mathrm{HS})$. Parameters analyzed included Path velocity (VAP), prog. Velocity (VSL), Track Speed (VCL), Straightness (STR), Linearity (LIN), Sperm Count, Motility, Motile Cell. (STR = VSL/VAP). All values of the HB group were increased compared to the control group. On the other hand, the HS group showed a significant decrease in linearity and straightness compared to the control group, and the two groups that received heat shock showed decreased sperm count and quality due to testicular damage. However, the HB + HS group recovered the testes due to the antioxidant effect of HB and increased the sperm quality and number. Compared to the HS group, the HB + HS group showed significant increases in sperm count, motile cell, and motility. Value is mean \pm SD of 4 mice group (SPSS, LSD, Dunnett T3, $n=20$ ), ${ }^{*} p<0.05$ vs. the control group, ${ }^{*} p<0.05$ vs. the HB group. 

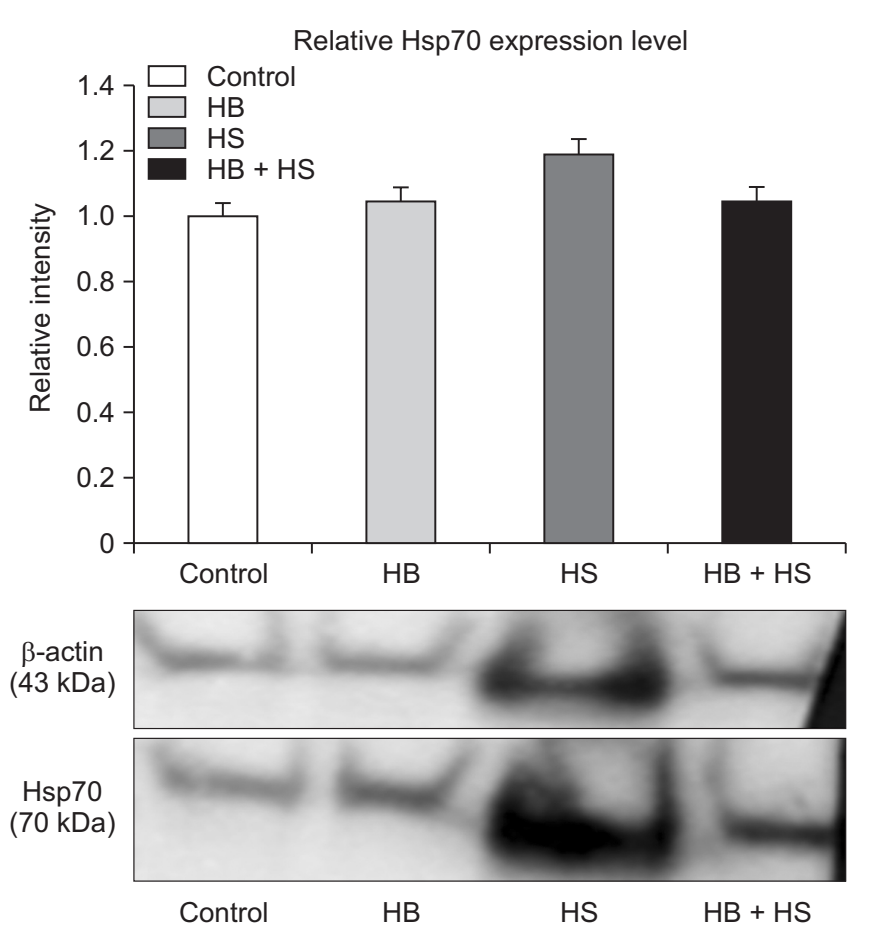

Fig. 4. Effects of Lonicera caerulea and heat stress-treated male mice on Hsp70 expression in testis. The expression level of Hsp70 was highest in the HS group compared to the control group, and the expression level of Hsp70 was increased in the $\mathrm{HB}+\mathrm{HS}$ group compared with the expression level of bactin. In addition, the HS group increased the amount of Hsp70 expression in order to protect the testicular tissue by heat stress. Similarly, the HB + HS group also increased Hsp70, but the testes were protected by $\mathrm{HB}$, so the Hsp70 expression was relatively low compared to the HS group. The HB group showed a similar expression level to the control group. This means that $\mathrm{HB}$ does not directly affect Hsp70. There are no significant differences. Values are the mean \pm SD of 4 mouse groups (SPSS, LSD, Dunnett T3, $n=20$ ).

in paraffin. Then, all samples were cut to a thickness of 4 $\mu \mathrm{m}$. Then, the sections were deparaffinized, rehydrated, and $\mathrm{H} \& \mathrm{E}$ stained.

\section{DISCUSSION}

When heat shock is applied to the testicles, ROS is generated, and the antioxidant effect of cells is reduced, resulting in a continuous increase in oxidative stress (Paul et al., 2009). The increased oxidative stress induces germ cell transformation and eventually progresses to germ cell apoptosis, which leads to sperm DNA destruction, testicular tissue deformation, and infertility (Houston et al., 2018). Therefore, heat damage to the testicles is a very fatal problem. Based on the previous results, we studied the

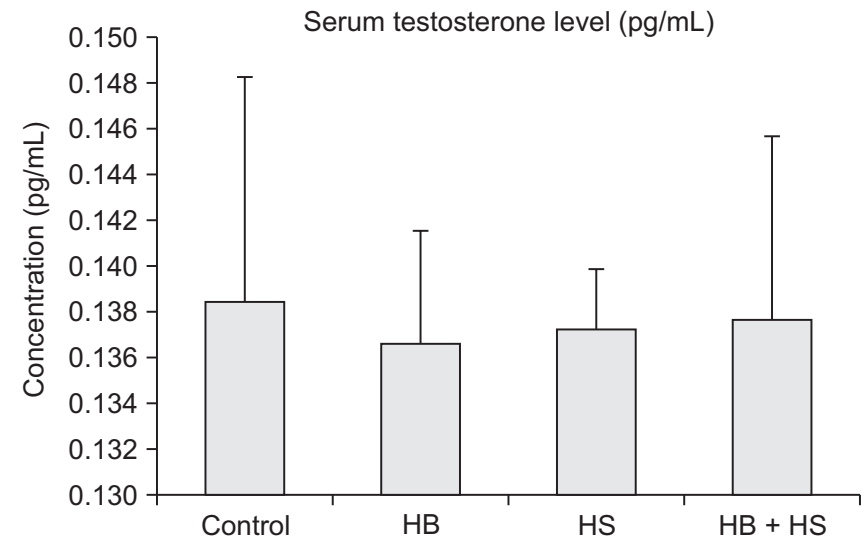

Fig. 5. Effects of Lonicera caerulea on serum testosterone levels in Heat stress-treated male mice. Serum Testosterone Level $(\mathrm{ng} / \mathrm{mL})$ in control group (C), Honey berry group (HB), Heat shock group (HS), Honey berry + Heat shock group (HB + HS). Compared to the control group, all groups showed similar levels of serum testosterone, they were not significantly affected by thermal shock. There are no significant differences. Values are the mean \pm SD of 4 mouse groups. (SPSS, LSD, Dunnett T3, $n=$ 20).

antioxidant effect of L. Caerulea and the recovery effect on testicular damage caused by thermal shock.

First, in the weight measure, relative body weight was decreased in the HS group compared to the control group, and the HB group and $\mathrm{HB}+\mathrm{HS}$ group increased. It was confirmed that the HB + HS group significantly increased body weight. This means that HB is not toxic in mice (Kim et al., 2015). In addition, in the HS group, heat shock damaged the testicles of mice, leading to overall weight loss. On the other hand, the $\mathrm{HB}+\mathrm{HS}$ group that received heat shock like the HS group gained more weight. So, you can see that HB has repaired the damage caused by thermal shock.

In the relative organ weight, there was little difference between each group for liver, and in the adrenal gland weight results, compared to the control group, the HS group showed a decrease in weight, and the HB + HS group showed an increase in weight. This can predict that the adrenal glands were also damaged as the hormone levels were disrupted due to the damage to the testicles caused by heat shock, and it is an indicator that can indirectly confirm that $\mathrm{HB}$ protects and recovers the testicles from heat shock.

There were no significant differences between groups in the spleen, kidney, heart, lung and salivary gland results. This is because, in the case of the preceding organs, 

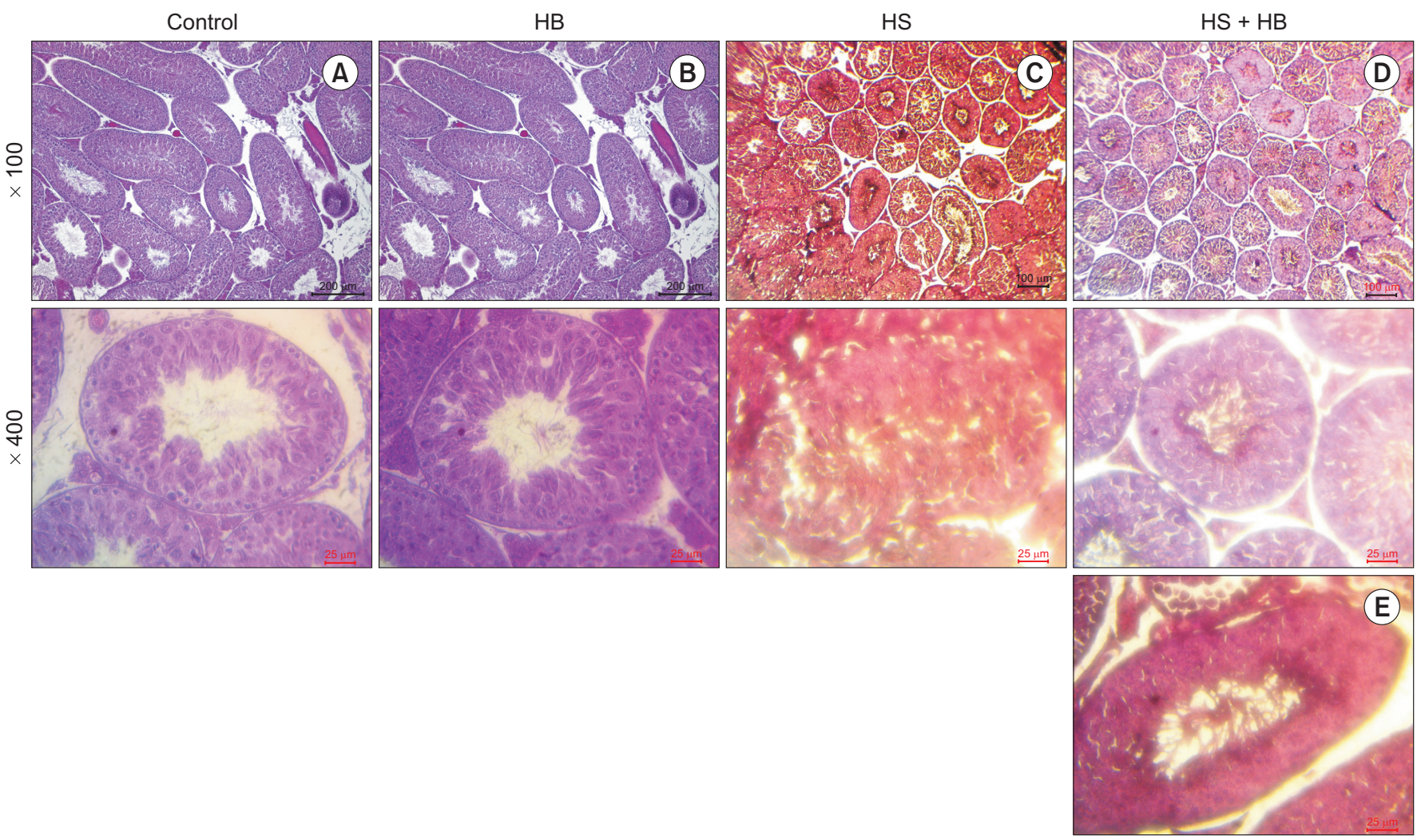

Fig. 6. H\&E staining of testis tissue from heat-stress treated male mice. A (control), B (Honey berry), C (Heat shock), D (Honey berry Heat shock), E (Honeyberry Heat shock $\times 400$ ) (A) Normal testis (B) Normal sperm number is more than control in seminiferous tubule lumen, continuous basement membrane and thick seminiferous tubule (C) Thickness of germinal epithelium is thin, internal bleeding, lack of seminiferous tubule's sperm, severe necrosis and degeneration of seminiferous tubule (D) Restore of seminiferous tubule's destruction, production of normal semen in the seminiferous tubule, continuous basement membrane, some of necrosis and degeneration (E) Despite of internal bleeding, production of semen in seminiferous tubule, continuous basement membrane.

there is little or no damage from thermal shock as they do not directly affect sex hormones. On the other hand, in the case of testes, the weight increased in the HB group and HB + HS group compared to the control group. The reason for the increase in testicular weight seems to be that the testicles were strengthened by the antioxidant effect of HB and a lot of vitamins. It was confirmed that the weight of the HS group was reduced compared to the control group by thermal shock.

In the neutrophil results of WBC differential count, it was confirmed that the HS group significantly increased the number of neutrophils than the control group (Oehler et al., 2001). Thermal shock is applied to the testicular tissue, and the number of neutrophils increases due to tissue damage and bleeding. In addition, the neutrophil results of the HB group and $\mathrm{HB}+\mathrm{HS}$ group were significantly decreased compared to the HS group, and there was no significant difference with the control group. Lym- phocyte, monocyte, eosinophil, and basophil were not significantly different from the control group. Therefore, it was confirmed that HB had insignificant effect on immune cells.

In the CASA results, the sperm count value was increased in the HB group compared to the control. However, there is no significant difference. In the HS group and HB + HS group, it was found that the decrease was due to thermal shock (Sailer et al., 1997; Houston et al., 2018). In addition, compared to the HS group, the HB + HS group significantly increased the sperm count, indicating that the testicular damage caused by thermal shock was repaired. It can be confirmed that the results of motility and motile cells were significantly increased in the HB + HS group compared to the HS group.

In the values of LIN and STR, the HS group significantly decreased compared to the control group, and it was confirmed that the thermal shock caused serious damage 
Kang and Kim. L. Caerulea has anti-oxidant and thermal protective activity

to the testicles. The results of VAP, VCL, and VSL showed similar results in all groups, and there was no significant difference.

Hsp70 protects cells from heat and oxidative stress. The HS group had the highest expression of Hsp70 in the Western blot results (Baek et al., 2019; Shen et al., 2019). Although the expression level of $\beta$-actin was high, the expression level of Hsp70 was increased compared to $\beta$-actin in the HB + HS group. This means that, despite the antioxidant effect of $\mathrm{HB}$, the increase in Hsp70 of the $\mathrm{HB}+\mathrm{HS}$ group means that $\mathrm{HB}$ does not directly affect Hsp70.

In the serum testosterone level results, all groups showed lower result values than the control group, but there was no significant difference. In addition, there was no concentration-dependent result on the expression levels of Hsp70 (Salmani et al., 2020). In the HB + HS group, HB protects the testes from heat shock and maintains testosterone levels but does not directly affect hormones like Hsp70.

In H\&E staining analysis, the control group showed normal testicular tissue shape. In the HB group, the number of sperms observed in the seminiferous tubule lumen was higher than in the control group, which is consistent with the CASA sperm count result. In addition, the seminiferous tubule and basement membrane are more continuous than the control group, and the germinal epithelium is thicker. In the HS group, the germinal epithelium was thin, with unclear boundaries, and internal hemorrhage was observed. In addition, decreased sperm count, tubular necrosis, and degeneration were observed in the seminiferous tubule lumen, supporting evidence for decreased testicular weight and decreased CASA values compared to the control group. In the HB + HS group, recovery of destroyed seminiferous tubules and normal spermatogenesis were observed in seminiferous tubules, and most recovered from thermal shock except for some seminiferous tubules (Akintayo et al., 2020; Thanh et al., 2020). The results confirmed that $\mathrm{HB}$ effectively restores and protects the testicles against thermal shock.

As a result, it has been demonstrated that $\mathrm{HB}$ protects and recovers the testes from oxidative stress and thermal stress against thermal shock both body weight and histology. Also, HB has no direct effect on hormones. This indicates that $\mathrm{HB}$ does not act as an endocrine disruptor. Therefore, HB has an effective preventive and antioxidant action against heat shock-induced testicular damage.

\section{CONCLUSION}

Infertility problems among young men are increasing worldwide. There are many causes of infertility, but the most common is direct exposure of the testicles to heat. Thermal shock generates thermal stress in the testicles and continuously forms ROS to generate oxidative stress, which continuously damages the testicles. Prolonged damage leads to histological changes in the testes, damage to sperm DNA, and potential infertility. In order to solve the serious problem of testicular damage caused by heat stress, many methods for protecting and repairing the testicles are being studied. However, previous studies did not effectively repair the testicular damage caused by thermal shock. Therefore, the purpose of this study was to protect and restore the testicles by oral administration of $\mathrm{HB}$ after exposing the testes to heat stress to prove the antioxidant effect of L. Caerulea Efficacy has been proven. Through the previous results, in the case of the $\mathrm{HB}+$ HS group that received heat shock like the HS group, the weight and testicular tissue weight loss were overcome, and the weight increased. In addition, despite the testicular tissue damage caused by heat stroke, the CASA results showed that all sperm count, motility, and motile cell levels were significantly increased compared to the HS group due to the antioxidant effect of HB. As supporting the analysis of the weight measure and CASA results, the HB + HS group was not significantly different from the control group as the testicular tissue was protected by the antioxidant effect of HB despite the heat shock in the WBC count results, and the H\&E results showed no significant difference. Compared with the HS group, the testicular tissue of the $\mathrm{HB}+\mathrm{HS}$ group was recovering like that of the control group. In the results of $17 \beta-H S D, H s p 70$ and serum testosterone, there was no significant difference in the results of all groups. This means that HB has no effect on hormones. Results of Hsp70 and serum testosterone protected the testis from heat stress without affecting hormonal effects on the efficacy of HB. Nevertheless, there were some shortcomings in the experiment. $17 \beta-\mathrm{HSD}$ and SOD2 explain the correlation between Hsp70 and testosterone. However, in this study, experiments were not conducted on both enzymes. Therefore, we intend to confirm and supplement the expression level of the enzyme 
through the next study. In conclusion, our study showed that $\mathrm{HB}$ effectively protects and repairs damaged testicles using antioxidant effects against heat stress-induced testicular tissue damage.

Author Contributions: Conceptualization, D.H.K., and D.Y.K.; methodology, D.H.K., and D.Y.K.; investigation, D.H.K., and D.Y.K.; data curation, D.H.K, and D.Y.K.; writing-original draft preparation, D.H.K., and D.Y.K.; writing-review and editing, D.Y.K.; supervision, D.Y.K.; project administration, D.Y.K.; funding acquisition, D.Y.K.

Funding: This work was supported by the Basic Science Research Program through the National Research Foundation of Korea (NRF) funded by the Ministry of Education (Project No. 2017R1A2B1010690).

Ethical Approval: Not applicable.

Consent to Participate: Not applicable.

Consent to Publish: Not applicable.

Availability of Data and Materials: Not applicable.

Acknowledgements: None.

Conflicts of Interest: No potential conflict of interest relevant to this article was reported.

\section{REFERENCES}

Ahn JS, Ryu HS, Jung SE, Shin BJ, Won JH, Um TG, Oh H, Kim $\mathrm{SH}$, Ryu BY. 2020. Expression profile of spermatogenesis associated genes in male germ cells during postnatal development in mice. J. Anim. Reprod. Biotechnol. 35:289-296.

Akintayo A, Liang M, Bartholdy B, Batista F, Aguilan J, Prendergast J, Sabrin A, Sundaram S, Stanley P. 2020. The Golgi glycoprotein MGAT4D is an intrinsic protector of testicular germ cells from mild heat stress. Sci. Rep. 10:2135.

Alotaibi MF, Al-Joufi F, Abou Seif HS, Alzoghaibi MA, Djouhri L, Ahmeda AF, Mahmoud AM. 2020. Umbelliferone inhibits spermatogenic defects and testicular injury in lead-intoxicated rats by suppressing oxidative stress and inflammation, and improving Nrf2/HO-1 signaling. Drug Des. Devel. Ther. 14:4003-4019.

Amann RP and Waberski D. 2014. Computer-assisted sperm analysis (CASA): capabilities and potential developments.
Theriogenology 81:5-17.e1-3.

An G, Park H, Song G, Lim W. 2021. Developmental toxicity of dimethachlor during zebrafish embryogenesis mediated by apoptosis and oxidative stress. J. Anim. Reprod. Biotechnol. 36:2-8.

Andrade JMM and Fasolo D. 2014. Polyphenol antioxidants from natural sources and contribution to health promotion. In: Watson RR, Preedy VR, Zibadi S (Eds.), Polyphenols in Human Health and Disease, Vol. 1, Amsterdam, Academic Press, pp. 253-265.

Baek YC, Kim M, Jeong JY, Oh YK, Lee SD, Lee YK, Ji SY, Choi H. 2019. Effects of short-term acute heat stress on physiological responses and heat shock proteins of Hanwoo steer (Korean cattle). J. Anim. Reprod. Biotechnol. 34:173-182.

Cai H, Qin D, Peng S. 2021. Responses and coping methods of different testicular cell types to heat stress: overview and perspectives. Biosci. Rep. 41:BSR20210443.

Chang KH, Ercole CE, Sharifi N. 2014. Androgen metabolism in prostate cancer: from molecular mechanisms to clinical consequences. Br. J. Cancer 111:1249-1254.

Cohen S, Nathan JA, Goldberg AL. 2015. Muscle wasting in disease: molecular mechanisms and promising therapies. Nat. Rev. Drug Discov. 14:58-74.

Dissanayake DMIH, Keerthirathna WLR, Peiris LDC. 2019. Male infertility problem: a contemporary review on present status and future perspective. Gend. Genome 3:2470289719868240.

Durairajanayagam D, Agarwal A, Ong C. 2015. Causes, effects and molecular mechanisms of testicular heat stress. Reprod. Biomed. Online 30:14-27.

Hamilton TR, Mendes CM, de Castro LS, de Assis PM, Siqueira AF, Delgado Jde C, Goissis MD, Muiño-Blanco T, CebriánPérez JÁ, Nichi M, Visintin JA, Assumpção ME. 2016. Evaluation of lasting effects of heat stress on sperm profile and oxidative status of ram semen and epididymal sperm. Oxid. Med. Cell. Longev. 2016:1687657.

Hidalgo GI and Almajano MP. 2017. Red fruits: extraction of antioxidants, phenolic content, and radical scavenging determination: a review. Antioxidants (Basel) 6:7.

Houston BJ, Nixon B, Martin JH, De Iuliis GN, Trigg NA, Bromfield EG, McEwan KE, Aitken RJ. 2018. Heat exposure induces oxidative stress and DNA damage in the male germ line. Biol. Reprod. 98:593-606.

Jang HY, Jin HA, Lee HY, Kim DJ, Cheong HT, Kim JT, Park IC, Park CK, Yang BK. 2009. Curcumin and Vit. E alleviate alone or synergetically hydrogen peroxide induced-oxidative stress on boar sperm characteristics during in vitro storage. Reprod. Dev. Biol. 33:273-281.

Kim EJ, Dang LC, Nyiramana MM, Siregar AS, Woo MS, Kim CW, Kang D. 2021. TRPV1 activation induces cell death of TM3 mouse Leydig cells. J. Anim. Reprod. Biotechnol. 36:145-153.

Kim HS, Park SI, Choi SH, Song CH, Park SJ, Shin YK, Han CH, Lee YJ, Ku SK. 2015. Single oral dose toxicity test of blue honeysuckle concentrate in mice. Toxicol. Res. 31:61-68.

Kim J and Keum YS. 2016. NRF2, a key regulator of antioxidants 
with two faces towards cancer. Oxid. Med. Cell. Longev. 2016:2746457.

Labrie F, Luu-The V, Lin SX, Labrie C, Simard J, Breton R, Bélanger A. 1997. The key role of 17 beta-hydroxysteroid dehydrogenases in sex steroid biology. Steroids 62:148-158.

Liu S, You L, Zhao Y, Chang X. 2018. Wild Lonicera caerulea berry polyphenol extract reduces cholesterol accumulation and enhances antioxidant capacity in vitro and in vivo. Food Res. Int. 107:73-83.

Molina AK, Vega EN, Pereira C, Dias MI, Heleno SA, Rodrigues P, Fernandes IP, Barreiro MF, Kostić M, Soković M, Barreira JCM, Barros L, Ferreira ICFR. 2019. Promising antioxidant and antimicrobial food colourants from Lonicera caerulea L. var. Kamtschatica. Antioxidants (Basel) 8:394.

Oehler R, Pusch E, Zellner M, Dungel P, Hergovics N, Homoncik M, Eliasen MM, Brabec M, Roth E. 2001. Cell typespecific variations in the induction of hsp70 in human leukocytes by feverlike whole body hyperthermia. Cell Stress Chaperones 6:306-315.

Paul C, Teng S, Saunders PT. 2009. A single, mild, transient scrotal heat stress causes hypoxia and oxidative stress in mouse testes, which induces germ cell death. Biol. Reprod. 80:913-919.

Sailer BL, Sarkar LJ, Bjordahl JA, Jost LK, Evenson DP. 1997. Effects of heat stress on mouse testicular cells and sperm chromatin structure. J. Androl. 18:294-301.

Salmani S, Razi M, Sarrafzadeh-Rezaei F, Mahmoudian A. 2020. Testosterone amplifies HSP70-2a, HSP90 and PCNA expression in experimental varicocele condition: implication for DNA fragmentation. Reprod. Biol. 20:384-395.

Shahat AM, Rizzoto G, Kastelic JP. 2020. Amelioration of heat stress-induced damage to testes and sperm quality. Theriogenology 158:84-96.

Shen H, Fan X, Zhang Z, Xi H, Ji R, Liu Y, Yue M, Li Q, He J. 2019. Effects of elevated ambient temperature and local testicular heating on the expressions of heat shock protein 70 and androgen receptor in boar testes. Acta Histochem. 121:297-302.

Sochor J, Jurikova T, Pohanka M, Skutkova H, Baron M, Tomaskova L, Balla S, Klejdus B, Pokluda R, Mlcek J, Trojakova Z, Saloun J. 2014. Evaluation of antioxidant activity, polyphenolic compounds, amino acids and mineral elements of representative genotypes of Lonicera edulis. Molecules 19:6504-6523.

Sun J, Yin B, Tang S, Zhang X, Xu J, Bao E. 2019. Vitamin C mitigates heat damage by reducing oxidative stress, inducing HSP expression in TM4 Sertoli cells. Mol. Reprod. Dev. 86:673-685.

Suresh S, Prithiviraj E, Venkatalakshm N, Ganesh MK, Ganesh L, Lee HJ, Prakash S. 2011. Spermatogenic and antioxidant potential of Mucuna prureins (L.) in epididymal spermatozoa: a dose dependent effect. Reprod. Dev. Biol. 35:441-447.

Thanh TN, Van PD, Cong TD, Minh TL, Vu QHN. 2020. Assessment of testis histopathological changes and spermatogenesis in male mice exposed to chronic scrotal heat stress. J. Anim. Behav. Biometeorol. 8:174-180.

Vijayprasad S, Bb G, Bb N. 2014. Effect of vitamin C on male fertility in rats subjected to forced swimming stress. J. Clin. Diagn. Res. 8:HC05-HC08.

Zhou Y, Jiang Z, Lu H, Xu Z, Tong R, Shi J, Jia G. 2019. Recent advances of natural polyphenols activators for Keap1-Nrf2 signaling pathway. Chem. Biodivers. 16:e1900400. 